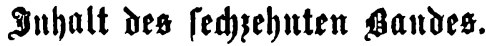

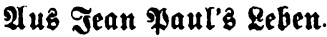

Erfte borlejung.

Wonfiebel - Eeburt - Brofbater . . . . . . . . . . 3

\section{Bweite Worlefung,}

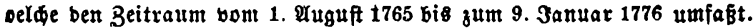

- 3obik - Dorfibbllen . . . . . . . . . . . . . . . . 14

Dritte Đorlefung und iret Beilagen.

Gdwarzenbađ all ber Sante - SuB - Rettor - Mbenbmabl . . . . . 55

\section{Fortję̧ung von Crnft Förfter.}

I. Bumnafialjąre. Freunbe. Iutorberuf. 1779-1781 . . . . . . 73

II. Uniberfitätzeit. Grönlänbifde anb anbere $\mathfrak{B r o z e f f e . ~ R e b e n s r e g e l n . ~}$ 1781-1782 . . . . . . . . . . . . . . . . . . . . 99

III. Sdulmeifteramt. Erotiffe Itabemie. Dtto. Die unfidtbare Loge. 1783-1793 . . . . . . . . . . . . . . . . . . . . 132

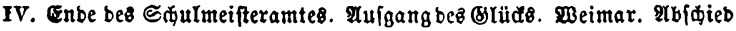
von ఏof. 1794-1797 . . . . . . . . . . . . . . . . . . . 154

V. Reipzig. Weimar. Berlin. Riebe. SSipfelpuntt ber Poefie unb tes Elüts. Meiningen. Roburg. $1797-1804$. . . . . . . . . 171

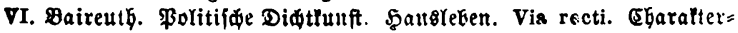
fltge. 1804-1813. . . . . . . . . . . . . . . . . . . 192 
Gette

VII. Beginn bes Reifelebens. 3acobi. Deutfílanbs unb eigneb Exfaxten.

Maria. - 1814 . . . . . . . . . . . . . . . . . . . 236

VIII. Wanberjabre. Regensburg 1816. Бeibelberg 1817. Franlfurt 1818.

Stuttgart; \&jbiфau 1819. MAinđen 1820 . . . . . . . . . . 2E4

L. Enbe. De Sobne Tob 1821. Dregben 1822. Rurnderg 1823-1826.

Iob. . . . . . . . . . . . . . . . 279 